\title{
Human fatigue and the crash of the airship Italia
}

\author{
Gregg A. Bendrick, ${ }^{1}$ Scott A. Beckett ${ }^{2}$ \& Elizabeth B. Klerman ${ }^{2,3}$ \\ 1 Neil A. Armstrong Flight Research Center, National Aeronautics and Space Administration, PO Box 273, Mailstop 4822, Edwards Air Force Base, \\ CA 93523-0273, USA \\ 2 Division of Sleep and Circadian Disorders, Brigham and Women's Hospital, 221 Longwood Avenue, Boston, MA 02115, USA \\ ${ }^{3}$ Division of Sleep Medicine, Harvard Medical School, 221 Longwood Avenue, Boston, MA 02115, USA
}

\section{Keywords}

Sleep; Nobile; polar exploration; aviation history; human error; mishap.

\section{Correspondence}

Gregg A. Bendrick, Armstrong Flight

Research Center, National Aeronautics and Space Administration, PO Box 273, Mailstop 4822, Edwards Air Force Base, CA 93523, USA. E-mail: gregg.a.bendrick@nasa.gov

\begin{abstract}
The airship Italia, commanded by General Umberto Nobile, crashed during its return flight from the North Pole in 1928. The cause of the accident was never satisfactorily explained. We present evidence that the crash may have been fatigue-related. Nobile's memoirs indicate that at the time of the crash he had been awake for at least $72 \mathrm{~h}$. Sleep deprivation impairs multiple aspects of cognitive functioning necessary for exploration missions. Just prior to the crash, Nobile made three command errors, all of which are of types associated with inadequate sleep. First, he ordered a release of lift gas when he should have restarted engines (an example of incorrect data synthesis, with deterioration of divergent thinking); second, he inappropriately ordered the ship above the cloud layer (a deficiency in the assessment of relative risks); and third, he remained above the cloud layer for a prolonged period of time (examples of attention to secondary problems, and calculation problems). We argue that as a result of these three errors, which would not be expected from such an experienced commander, there was no longer enough static lift to maintain level flight when the ship went below the cloud layer. Applying Circadian Performance Simulation Software to the sleep-wake patterns described by Nobile in his memoirs, we found that the predicted performance for someone awake as long as he had been is extremely low. This supports the historical evidence that human fatigue contributed to the crash of the Italia.
\end{abstract}

To access the supplementary material for this article, please see the supplementary files under Article Tools, online.
Interest continues to this day in the fate of the airship Italia, its mission to the North Pole, its crash en route back to base, the subsequent search and rescue effort and the political fallout after the survivors returned home in 1928 (Cross 2002; Aas 2005; Peroni 2009). The causes of the crash are still the subject of debate. Analyses of the causes can perhaps explain some of the surprising actions taken by its commander and may provide useful lessons for polar operations of the present age. This paper examines the series of events before the crash with an emphasis on the human factors involved and the role human sleep physiology may have played on its commander, General Umberto Nobile.

\section{Narrative}

General Umberto Nobile (1885-1978) was an aeronautical engineer and airship pilot who held a commission in the Italian Air Force. In 1926, he flew the semi-rigid dirigible Norge - an airship he had designed and builtover the North Pole, together with Norwegian Roald Amundsen, American Lincoln Ellsworth and a supporting crew. They were the first to perform such a feat in an airship. Nobile then conceived of a slightly larger airship called the Italia, for which he planned both a flight to the North Pole and stationary time at the site, during which he would discharge a scientific party to perform Arctic 


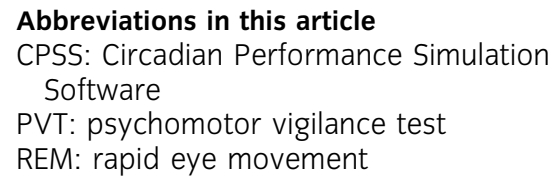

research. The plan was to later retrieve the scientific party using the Italia.

After securing necessary funding and overcoming various socio-political obstacles, Nobile completed construction of the Italia and the selection of its crew. They deployed from Milan on 15 April 1928, on their way to a forward operating base at Ny-Ålesund, Spitsbergen, in the Arctic archipelago of Svalbard. The multiple-leg trip took several days, with delays due to poor weather and damage during flight that necessitated repair. The airship reached Ny-Ålesund on 6 May.

Nobile planned five flights exploring different areas of the Arctic, each originating from the base. The crew attempted its first trip to an unexplored region of the Arctic on 11 May, but had to return after only $8 \mathrm{~h}$ because of ice formation on the ship's envelope and damage to the control cables as a result of the extreme environmental conditions. On their second attempt on 15 May, weather conditions were markedly improved and the attempt was successful. They flew a 2500-mile flight through the uncharted area known then as Nicholas II Land (Severnaya Zemlya) and gathered significant scientific data from this region. The ship returned to base on 18 May after a trip that had taken approximately $60 \mathrm{~h}$.

Nobile and his crew began the polar mission early in the morning on 23 May. After some relative problem-free sailing, they reached the North Pole on 24 May. However, the winds were too high at that time to safely discharge a landing party onto the ice, so after commemorating the event the crew began their journey back to base. During this return, they faced strong and persistent head winds. Approximately $53 \mathrm{~h}$ into the flight, at about 09:25 on the morning of 25 May, the ship began to lose altitude because of a jammed-possibly frozen-elevator control mechanism. Recognizing the emergency, Nobile ordered the engines stopped to arrest the uncontrolled descent. Without forward thrust, the Italia's descent slowed and eventually stopped, narrowly avoiding a crash of the airship onto the ice. The ship eventually began to rise because of the static lift produced by the ship's hydrogen lift gas. Nobile initially ordered a release of gas in an attempt to stop, or at least slow, this ascent. But as they continued to rise, he acquiesced to a suggestion to continue above the ice fog and clouds in order to obtain a navigational reading on the sun. The ship remained above the clouds for as long as $30 \mathrm{~min}$. After ordering the engines restarted, Nobile and crew descended again back into the clouds to continue the return home. Shortly thereafter, the ship once again began to lose altitude. Nobile was not able to correct this descent. The Italia crashed onto the ice at 10:33 on the morning of 25 May at a spot approximately $250 \mathrm{~km}$ from its base in Ny-Ålesund. When the ship hit the ice, the envelope containing the bags of hydrogen gas broke away from the gondola beneath it and floated away. On the ice, one crew member in the gondola was killed upon impact, but nine others-including Nobile-survived the crash. Nobile and several others were injured. They managed to retrieve the ship's radio and used it to alert others of their status. A multinational search and rescue effort ensued. The famed Roald Amundsen coordinated an airborne search and rescue effort, but was lost in the attempt, presumably having crashed in the Arctic. Eventually, the survivors were spotted by a Swedish pilot, Einar Lundborg, who landed near their survival tent. Lundborg had room in his aircraft to transport only one person at a time, and Nobile was the one he brought home, ostensibly to better coordinate the rescue effort from an Italian Navy support ship anchored at Ny-Ålesund. On its return trip to retrieve the remaining survivors, the rescue plane crashed, and Lundborg was now among those who awaited rescue. Eventually, a Russian ice-breaker, the Krasin, made its way to the survivors, who were retrieved on 12 July (Nobile 1961; Simmons 1965; Cross 2002).

To investigate what caused the crash, the Italian government appointed a Commission of Inquiry, led by Admiral Cagni, who had taken part in a ground-based polar expedition earlier in his career. The findings of the Commission were made public on 3 March 1929 and were eventually released in book format (Cagni 1930). The Commission was harshly critical of Nobile in virtually every aspect of his conduct of the expedition. With regard to the cause, the Commission relied on the analysis of General Crocco, an expert on dirigibles, who determined that the sudden loss of altitude and subsequent crash were due to deficient piloting skills on the part of Nobile. Specifically, he faulted Nobile for not keeping the prow of the ship against the wind, and as a result allowing the wind to drive the airship into the ice at approximately $100 \mathrm{~km}$ per hour. The Commission concluded that the expedition lacked "an experienced pilot possessing that trained capacity which is to be acquired only by a long course in navigation" (Anonymous 1930: 3). They unanimously concluded that "the precise responsibility for the disaster rests on the commander of the airship Italia for an erroneous manoeuvre ... In all the conduct of the expedition up to the disaster and after, General Nobile has shown himself to have limited 
technical qualities as a pilot and a negative capacity for command" (Anonymous 1930: 3).

While Nobile was blamed solely for the crash on account of his supposed ineptness as an airship pilot, he was not a novice with regard to airship piloting. He was an accomplished aeronautical engineer, and at the time of the crash he had most likely accrued more flight time than anyone in the unique design of a semi-rigid dirigible in the unforgiving environment of the Arctic. Moreover, Nobile had made political enemies in the course of his career, possibly because of his strong advocacy of the airship as opposed to airplanes as the more effective means of utilizing national air power (Cross 2002). It could, therefore, have been of political advantage to show that Nobile was an incapable pilot, and one whose opinion did not matter. It is worthwhile to reassess elements of the crash sequence and to examine other possible precipitants.

\section{Causes of the crash}

According to his memoirs, Nobile believed the cause of the crash was a frozen, lifting gas pressure relief valve stuck in the open position. As the ship began its final, uncommanded descent, Nobile had ordered crew member Alessandrini to check on the automatic valves, fearing that ice had formed on the valve seats, making it impossible for them to close and so causing a sudden, involuntary loss of hydrogen lift gas (Nobile 1961). In this case, the valve would have become frozen when reentering the fog bank, after the crew had obtained the sextant reading on the sun while above the cloud layer.

Nobile's hypothesis is not without merit. The phenomenon had occurred several times before with other Italian dirigibles that flew in winter environments, or at higher, colder altitudes. The problem was also known to occur on English airships (Nobile 1961). However, it is probably not responsible for the loss of altitude and the crash of the Italia. First of all, in the memoirs of crewmember Trojani, who was in the gondola and monitoring the relevant pressure gauges at the time of the crash, it is stated that there was no sudden or significant loss of lift-gas pressure, which one would expect if a valve were stuck in an open position (Trojani 1964). Secondly, a frozen valve was unlikely because of specific design changes that Nobile himself had instituted for his Arcticcrossing airships. In his own memoirs, Nobile discusses his novel design, which reduced humidity in the valve (see Supplementary File, item 1).

A different cause of the crash was postulated several years later by Knut Eckener, a doctor of engineering and son of the famous airship designer Hugo Eckener. Knut
Eckener believed that Nobile lost a critical volume of the hydrogen lift gas when he ordered the ship to ascend above the clouds because the increase in altitude and thermal heating while the ship was in direct sunlight caused the gas to expand (Eckener 1958). The gas expansion would result in off-gassing through the automatic valves of the gas cells that were put in place to avoid an over-expansion and possible rupture of the gas cells.

Eckener suggests that there were two errors in the sequence of events leading to the crash: (i) attaining an altitude high enough to rise above the clouds and (ii) remaining above the clouds in direct sunlight, where the increasing temperature of the gas bags resulted in further gas expansion and ultimate loss through automatic valving (see Supplementary File, item 2). It is worth noting that Eckener did not realize or address the fact that Nobile had already ordered the release of some hydrogen lift gas before ascending above the clouds, which was done in order to slow a resulting ascent after the engines had been ordered stopped; this event will be discussed later. This earlier release of gas only reinforces Eckener's argument ascribing the cause of the crash ultimately to a critical loss of static lift.

Eckener's conclusion that a critical loss of lift gas led to the crash of the Italia is both plausible and valid. It is more probable than the frozen valve hypothesis of Nobile, and certainly more plausible than the claim of deficient piloting made by the Commission of Inquiry. The more intriguing question remains as to why a knowledgeable and experienced commander such as Nobile would make such a simple series of mistakes so as to lose a critical amount of lift gas? We postulate that the answer is human fatigue; this will be discussed in the following sections.

\section{Nobile and the crew's sleep-wake patterns}

By the time the Italia crashed onto the ice pack, Nobile and his crew were extremely sleep deprived. By the most conservative of estimates, Nobile himself had been awake for at least $72 \mathrm{~h}$. Specifically, one can estimate his sleep and wake periods from his memoirs (Nobile 1961). He notes that at noon on 22 May, he received a favourable weather report from the meteorological station in Tromsø. He, therefore, sent the crew to sleep, telling them to be in the hangar by 23:00 that night (i.e., the night of 22 May). Since it is inconceivable that Nobile would have had the crew assemble while he himself was still sleeping, one must conclude that Nobile himself would have been awake and in the hangar also, ready for flight by 23:00. Moreover, if Nobile did try to sleep at 
some point between noon, when he received the favourable weather report, and 23:00, when he had the crew assembled, he would have had at best only broken sleep because he notes that he had received several telegraphs from the meteorological station in Tromsø throughout this period advising him that the weather had remained unchanged. There is further evidence to conclude that Nobile had in fact not obtained any more sleep once he had awakened on the morning of 22 May, as will be discussed in more detail later.

In his memoirs, Nobile never mentions sleeping or taking a nap during the flight to the North Pole, the time spent there or the return trip towards home base. This is not an oversight or an omission of the narrative record, for in his memoirs Nobile himself gives a point-by-point account of the journey, using his log book written during the journey. At no point in this nearly minute-by-minute narrative does he mention the fact that he took a break, went to sleep or handed the command over to another while he himself rested. He does note, however, that on the morning of the crash two others (Pontremoli and Lago) were asleep while he was supervising everything. Likewise in his recollections, crewmember Trojani never mentions having observed Nobile sleeping during this flight (Trojani 1964). It is reasonable to conclude that Nobile forced himself to stay awake for the entire duration of the mission.

Ignoring the need for sleep appeared to be Nobile's standard practice on such missions, as he reports in his memoirs other incidents in which he worked extended hours, thereby depriving himself-and to a large extent, his crew-of sleep. For instance, while discussing his selection of crew members for the Norge expedition, which occurred prior to that of the Italia, Nobile broaches the idea of having a deputy who could take over command of the ship in order to afford himself a period of rest. But, he then dismisses the thought, stating:

Certainly, the presence of another expert pilot would have enabled me to rest from time to time, sparing me an uninterrupted vigil of 32 hours ... But, all things considered, I do not regret it. When responsibility is concentrated in a single person ... his attention is sharpened, his decisions are made swiftly and swiftly carried into effect. (1961: 23)

Ironically, Nobile was more inclined to bring on additional staff in order to allow other critical crew members (but not himself) to rest. While making preparations for the Italia expedition, he notes:

With Arduino, a chief motor engineer of great merit, and Caratti and Pomella, exceptionally able mechanics, the engines would undoubtedly be looked after in the best possible manner. It was only necessary to add a fourth man to allow adequate rest during our flights to this very important part of the crew. (1961: 103)

Nobile's comments suggest that he felt a good commander should not sleep at all during a flight, not even for a short period of time. Rather, such a commander must be at his place of command throughout the entire course of an expedition in the event an emergency developed. He apparently felt that with enough discipline, willpower and motivation, a person could overcome or at least delay the effects of sleep deprivation until there was an opportune time for recovery:

So once again I had to take over the elevator wheel [on the Norge], replacing Wisting, who was so tired that at times I saw him unconsciously closing his eyes ... I was very tired: I had not had a single moment to sit down and rest; there were times when I felt I could bear it no longer. I realized that my instinct of selfpreservation had vanished; if my own life had been the only one at stake, I would have let my eyes close in irresistible sleep. But the sense of responsibility was strong, and I could still find-I don't know how - strength to resist my physical exhaustion and stay glued to my post, with my eyes open and my mind alert, in a supreme effort of will-power. (1961: 76)

Likewise, when relating the last stages of the Norge expedition, Nobile notes:

By this stage of the flight, having slept only 3 hours out of the preceding 97, I was thoroughly exhausted; yet from somewhere I drew sufficient reserve of strength to make a landing. (1961: 94)

Nobile reflected the culture of his time, one in which the heroic mindset of an age of exploration was still very much alive. In this context, the true hero sacrifices material comforts and ignores physical needs in the higher interests of mission accomplishment.

Yet, despite his obvious motivation and devotion to duty, Nobile was not immune to the physiological consequences of sleep deprivation. He relates this fact in several different passages in his memoirs. One is at the end of the Norge expedition, when he notes after landing:

I was exhausted. For 60 hours I had been awake, without closing my eyes for a moment: good training, indeed, for the Polar flight! ... I could barely stand .... An hour later, in one of the salons of the palace, I could barely summon up 
strength to murmur a few words of thanks in reply to the addresses of welcome from the Agent of Foreign Affairs and the doyen of the professors. Immediately afterwards I dropped into bed in the room they had assigned to me. (1961: 40)

In preparation for another flight of the Norge, he notes:

I was tired. It had been a busy day: the sleepless night in the cold hangar and the inpatient waiting had worn me out. Towards six o'clock I could stand it no longer. I threw myself down on the floor of the control cabin. Someone passing by covered me with a rug, so that I should not feel the cold. (1961: 55)

And later, in preparation for a flight of the Italia, he states:

Tired as I was by my long watch, I went to sleep for a time in one of the rubber dinghies inside the hull, telling the officer on duty to wake me if anything happened ... they roused me after an hour or two. (1961: 121)

In yet another entry, he notes the effects of sleep deprivation on his crew on the Norge, where the effects were so pronounced that one crewmember started to hallucinate:

Except for the wireless operator Johnsen ... the other members of the expedition had very little sleep. In the last day, fatigue was at its height, and it was very difficult to keep alert: I remember several times catching the man at the elevator wheel with his eyes closed. Riiser-Larsen later described how he thought he saw a squadron of cavalry, where there was nothing but the empty ice. It was a dramatic situation indeed to find ourselves tired out, on the very day when we needed all our wits about us to bring the airship safely through the storm. (1961: 58)

And in a related context, he describes his own confused state of mind while landing the Norge:

I cannot attempt to give any details ... Who can tell what route we followed, or how we wound in and out through the fog? Even today I can still live through the emotions of this wild flight under the fog, without knowing where we were or where we were going; but the recollection is confused, as in a nightmare. I vividly remember only the most dramatic moments when a catastrophe seemed imminent. (1961: 74-75)

Nobile does not appear to realize that one's feeling of alertness can be deceiving in sleep deprivation conditions. At the outset of the mishap sequence of events that brought down the Italia, after having been continuously awake for almost $72 \mathrm{~h}$, he notes:

It was a really difficult situation. But - as always in similar circumstances-the difficulties had excited my energy: I did not feel tired, but even more alert than usual (1961: 151)

Unfortunately, self-assessment can be deceiving in these situations because during sleep restriction (i.e., multiple nights with insufficient sleep) and sleep deprivation (i.e., one continuous wake episode), self-assessed alertness is not an accurate assessment of cognitive performance on a group or individual level (Belenky et al. 2003; Van Dongen et al. 2003; Lo et al. 2012; Bermudez et al. 2016). Since individuals choose whether to continue their task or stop for caffeine or a nap based on their subjective assessment of alertness, this discrepancy between subjective alertness and objective performance can lead to serious errors and accidents.

The simple lack of sleep was not the only physiologic factor that Nobile mentions. There was also the effect of light, which itself can affect sleep. Nobile noted that the constant daylight prevented them from sleeping regularly and in the long run made them even more tired (Nobile 1961). Thus, the constant light would increase overall fatigue levels due to its disruption of any attempted sleep. Since the drive for sleep depends on both the length of time awake and the timing of endogenous circadian rhythms (Borbély 1982), and since light is the most potent stimulus for altering circadian rhythms (Duffy \& Czeisler 2009), the constant light might have negatively affected the amplitude or timing of Nobile's circadian rhythms, and thereby further reduced his alertness. This is discussed further below.

Nobile's own accounts relate that, during the Italia expedition, he and his crew experienced both acute sleep deprivation and chronic sleep restriction. Nobile probably did not realize what the scientific community has now learned from many years of sleep research - that sleep is a physiologic necessity and, without it, there is significant impairment of neurocognitive function (see review by Durmer \& Dinges 2005). To better understand how fatigue affected Nobile's cognition, problem-solving and decision-making, we review some specific elements of sleep physiology and their effects on human performance.

\section{Research on sleep and performance}

In the past 75 years, a great deal of scientific research has shed light on the physiology of sleep. Recording of the electrical activity of the brain (electroencephalography), muscle activity (electromyography) and eye movement 
(electro-oculography) has shown that there are two major stages of sleep: REM sleep and non-REM sleep.

During REM sleep, there are brief times during which eyes move rapidly while the electroencephalogram resembles that during the waking state. This is the time during which most dreams occur. REM sleep appears to be associated with the incorporation of memories and emotions from the previous day, linking them to memories and emotions from long-term memory. On the other hand, non-REM sleep is characterized by different distinct patterns of electrical activity in the brain and is associated with recovery and restoration of biochemical functions within and among brain cells (Porkka-Heiskanen et al. 2002; Lamond et al. 2007). A typical night's sleep will exhibit cycling between non-REM and REM sleep, with predominantly non-REM sleep in the early part of the sleep episode and predominantly REM sleep in the latter part (CSMR 2006).

Sleep is critical for the brain and for the rest of the body. When the sleep episode is shortened or eliminated, there are predictable detrimental effects on cognition, mood and performance, as well as immune function, metabolism and other physiological functions (Banks $\&$ Dinges 2007; Bianchi 2014). During times of total sleep loss (i.e., sleep deprivation), micro-sleeps occur. Microsleeps are short periods during which the brain is fully asleep, but the individual is not aware that he or she is asleep. They are involuntary, can last up to several seconds, and are correspondingly more frequent and longer in proportion to the amount of time one has been deprived of sleep (Carskadon 1993; Moller et al. 2006).

The timing and content of sleep are regulated primarily by two distinct processes - a homeostatic drive and a circadian drive (Borbély 1982). The homeostatic drive rises with increased amounts of time spent awake and dissipates during sleep over a course of several hours. This homeostatic drive, that is, sleep "pressure", can be measured in the sleep latency (i.e., the length of time to fall asleep, which is shorter with increased wake duration), as well as in the depth and duration of non-REM sleep, which increases with prior wake duration. Homeostatic sleep drive also has a longer term component, which is expressed during chronic sleep restriction and which is more pronounced during the circadian night time (Cohen et al. 2010). Multiple nights of sleep are required to restore performance during the day to predeprivation or pre-restriction levels (Belenky et al. 2003; Van Dongen et al. 2003; Cohen et al. 2010); it is not known how much sleep during the night is required to restore performance to baseline levels.

Distinct from the homeostatic drive, the circadian drive for sleep is generated by a group of cells at the base of the brain known as the suprachiasmatic nucleus of the hypothalamus. These cells act as an endogenous pacemaker that affects the timing of sleep, as well as hormone secretion, subjective alertness and objective performance, along with mood, gastrointestinal, cardiovascular and immune functions. Light is the most potent stimulus to the suprachiasmatic nucleus; the timing, duration and intensity of light are all factors in the effects of light on circadian timing and amplitude (Duffy \& Czeisler 2009). One hormone tightly regulated by the circadian pacemaker is melatonin, which is secreted by the pineal gland. Melatonin levels are low during the biological day, and elevated during the biological night, consistent with the circadian drive for sleep. Known as the "window of circadian low", the period of maximum melatonin secretion is associated with decreased alertness, reduced core body temperature and shortened sleep latency. This pattern can be disrupted by exposure to bright light at night, which suppresses melatonin secretion. In conditions of almost constant light, as in Arctic/Antarctic summers, changes in the diurnal rhythms of sleep, alertness and other physiology occur (Joern et al. 1970; Ross et al. 1995; Arendt 2012), probably as a result of multiple factors including altered circadian rhythms and the direct effects of light (Gander et al. 1991; Spencer et al. 1991; Rahman 2014).

When sleep deprived, and/or when in the window of circadian "low", cognitive slowing and lapses in attention can result in performance errors (Doran et al. 2001). For an individual living on a regular "day" schedule, the lowest performance and alertness would be approximately 04:00 to 06:00, when the circadian system is strongly promoting sleep (Dijk \& Czeisler 1994; Monk \& Carrier 1997). Subjective alertness and objective performance are affected by the nonlinear interactions of the length of time awake and the circadian rhythm; the longer one is awake, the stronger the circadian influence on subjective alertness and objective performance, as evidenced by multiple metrics of cognitive performance (Wyatt et al. 2004; Cohen et al. 2010; Bianchi 2014).

Performance is especially important in activities such as aviation, where an operator must be aware of, and respond to, a constantly changing set of circumstances. Fatigue-related decrements in higher order neurocognitive processing are seen as: (i) a general slowing of information processing, or the inhibition of "cognitive creativity", in which individuals resort to old, overlearned information-processing strategies in the face of new information, that is, increased perseveration and mental set rigidity (Harrison \& Horne 1999, 2000; Nilsson et al. 2005; Killgore et al. 2006; Alhola \& Paivi 2007; Monk 2007; Venkatraman et al. 2007; Maddox et al. 2009; Horne \& Moseley 2011; Libedinsky et al. 2013); 
(ii) impaired innovation; (iii) reduced ability to deal with the unexpected or with competing distractions, or with task information from multiple sources; (iv) reduced sensitivity to risk differences among options; (v) increasing risk tolerance; and (vi) ineffective communication (Durmer $\&$ Dinges 2005; Table 1). Because of its effect on performance, fatigue has been shown to be a cause or contributory factor in multiple aircraft accidents (NTSB 1994; Goode 2003; Gokhale 2010; Supplementary File, item 3).

There is also extensive evidence of the strong influence of circadian timing on errors and accidents. For example, accidents at the Three Mile Island and Chernobyl nuclear power plants, as well as the oil spill from the tanker Exxon Valdez, all occurred at around 04:00, the timing of circadian "low", when the circadian drive for sleep is strongest (Moss \& Sills 1981; NRC 1987; NTSB 1990). Motor vehicle accidents are also most likely during these periods of circadian "low" (Mitler et al. 1988; Pack et al. 1995). Moreover, if the endogenous circadian rhythm is not synchronized to environmental time-as occurs when rapidly crossing time zones, working night shifts or adhering to a rotating shift schedule-there are significant increases in errors, accidents and negative health consequences (Mitler et al. 1988; Pack et al. 1995).

The PVT is a 10 -min test measuring reaction time that has been well validated in sleep research. It is a useful tool in quantifying performance decrements that occur with both acute sleep deprivation and chronic sleep restriction (Dinges \& Powell 1985; Dinges \& Kribbs 1991; Belenky et al. 2003; Van Dongen et al. 2003; Cohen et al. 2010). For example, both PVT and sleep latency tests have shown that one's performance after 22-24 h of total sleep deprivation is equivalent to that of someone who is legally intoxicated with alcohol (Dawson \& Reid 1997; Roehrs et al. 2003). Other studies have shown that individuals given limited time to sleep over a period of 7-14 days demonstrate progressively decreasing performance (Belenky et al. 2003; Van Dongen et al. 2003), even while an individual's self-reported alertness does not continue to decline. Under conditions of sleep restriction, performance is close to normal for the first few hours after awakening, but then worsens significantly-especially if the individual is working at night (Cohen et al. 2010). It should be noted that the PVT is limited in its applicability, as it only measures specific vigilance-related aspects of performance; little is known about how performance on the PVT relates to performance on more complex tasks such as flying an airship, or performance as part of a larger crew (Caldwell et al. 2004; Roach et al. 2006).

\section{Fatigue modelling}

Human performance therefore demonstrates predictable patterns based on the duration of prior sleep and on the physiologic time of day. These and other relevant factors can be modelled with a mathematical algorithm that predicts overall performance relative to baseline for a normal individual, given the timing of sleep as well as the amplitude and relative time of circadian rhythms. These models can reveal a reasonable picture of the average person's expected performance levels, given a known sleep-wake pattern, along with estimated circadian rhythm and ambient light levels (Jewett \& Kronauer 1998, 1999; Jewett et al. 1999). Just as earthquake models cannot predict exactly where an earthquake will happen, but can be used to determine areas of increased likelihood of an earthquake, a mathematical model of circadian rhythm, sleep-wake schedules and performance can be used to predict times when performance would be expected to be low, and therefore when errors or accidents are more likely to occur. These mathematical models have

Table 1 Neurocognitive effects of sleep loss, adapted from Durmer \& Dinges (2005) and other sources.

- General slowing of information processing; the likelihood of error increases when there is time pressure to produce a response

- Slowed (increased) response time

- Increased errors of omission (i.e., behavioural lapses evident as failure to respond in a timely manner to a stimulus)

- Increased errors of commission (i.e., responses when no stimulus is present, or responses to the wrong stimulus)

- Decline of both short-term recall and working memory

- Reduced learning (acquisition) of cognitive tasks

- Impaired innovation, with inhibition of "cognitive creativity"

- Response perseveration on ineffective solutions (i.e., keep trying to do something even if it is not producing the desired result)

- Reduced ability to deal with the unexpected

- Reduced ability to deal with competing distractions or task information from multiple sources

- Growing neglect of activities judged to be non-essential (possibly resulting in a loss of situational awareness)

- Deterioration of performance requiring divergent thinking (i.e., problems with the evaluation of multiple potential solutions to a problem)

- Reduced sensitivity to risk differences among options (i.e., error in assessing relative risk of actions)

- Increased risk tolerance

- Ineffective communication

- Involuntary episodes of micro-sleep (i.e., very short sleep episodes) 
limitations. For instance, the models provide predictions for average populations, not for a single individual, and it is known that there are significant individual, trait-like differences in the vulnerability to sleep loss (Van Dongen et al. 2004) as well as factors not in the model (e.g., pain or environmental conditions such as noise or cold). Notwithstanding their inherent limitations, such models can still be a useful tool is assessing an overall picture of fatigue (Neri 2004; CASA 2014).

One such biomathematical tool is CPSS (www.sleep. med.harvard.edu/research/faculty-research/tools/cpss), which has been used to assist with planning sleep, work and rest cycles for astronauts aboard the Space Shuttle and the International Space Station (Whitmire et al. 2009). Such a model incorporates the effects of acute sleep deprivation and the circadian pacemaker, and can be used to modify the circadian oscillator's amplitude and timing in response to changing ambient light levels (Dean et al. 2009). Inputs to the CPSS model are sleepwake timing and light levels; outputs are the relative levels of objective performance and subjective alertness. The CPSS model currently does not include some known influences on performance and alertness, such as the effects of workload, stress or chronic sleep restriction.

We applied the CPSS model to the sleep-wake patterns described by Nobile in his memoirs, starting with the science and exploration flight to Severnaya Zemlya (Fig. 1). We started with the flight previous to the polar flight, as it is possible that a sleep debt had been incurred but not completely resolved during the days and nights at Ny-Ålesund on 18-23 May, before the crew started the polar flight. It is also possible that some of the predicted performance decrements may have been offset through the use of a stimulant such as caffeine; however, since we did not have specific information in this regard, it could not be included in the model.

Nobile (1961) noted that on the morning of 14 May, he received a favourable weather report, and so made preparations for the science and exploration flight. He notes that at 01:00 on 15 May "everything was ready", but they then experienced a delay while repairs were made to correct a defective oil flow:

And so we hung about for 12 hours in the hangar, in a suspense that tired mind and body far more than a day's flight. But in the end, at 1 p.m. on the 15 th we were ready, and at 1:20 we set off. (1961: 130)

The flight lasted until 18 May, when it landed back at Ny-Ålesund at 10:20. The flight duration was exactly $69 \mathrm{~h}$, and Nobile's period of continuous wakefulness for this mission is estimated to have been just shy of $100 \mathrm{~h}$. The predicted performance for someone awake that period of time is extremely low (Fig. 2), though Nobile and his crew did land the airship without incident.

This extreme sleep deprivation from the science flight is significant because one does not completely recover a significant sleep debt in just one sleep episode; several days

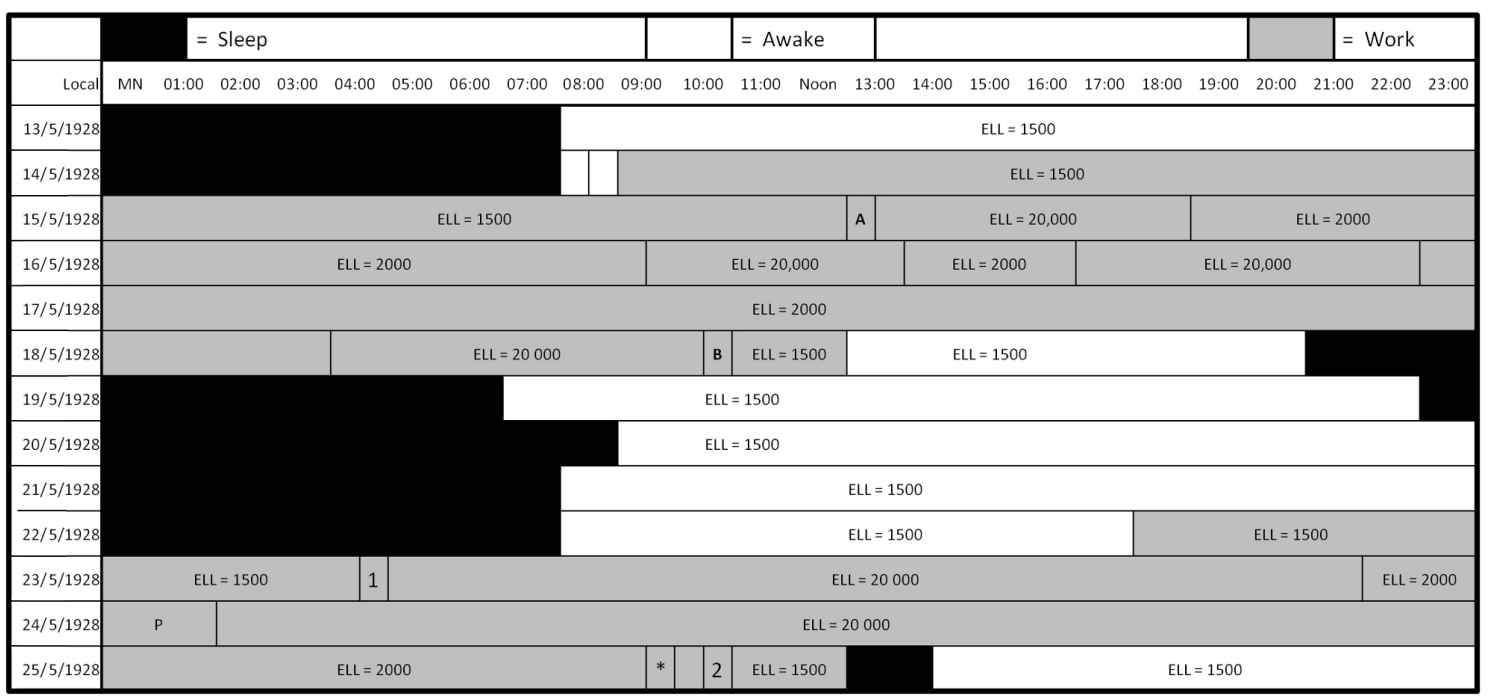

Fig. 1 Raster plot of Nobile's estimated sleep-wake-work cycles and light levels. Days are on the vertical axis and hours of the day on the horizontal axis. Black areas indicate periods of sleep, white areas indicate time spent awake on the ground and grey areas represent the flight. Estimated light levels (ELL) are shown for wake and flight segments. The timing of events A, B, 1, P and 2 are indicated: A is launch of the science and exploration flight; $\mathrm{B}$ is landing of the science and exploration flight; 1 is take-off of the polar flight; $\mathrm{P}$ is passage over the North Pole; and 2 is crash onto ice. The ELL were (i) for sleep, 5 lux; (ii) for daytime on the ground, 1500 lux; (iii) for flight in the clouds, 2000 lux; and (iv) for flight in clear skies, 20000 lux. The asterisk indicates the 30 min when the ELL was 20000 , before returning to 2000 lux. 


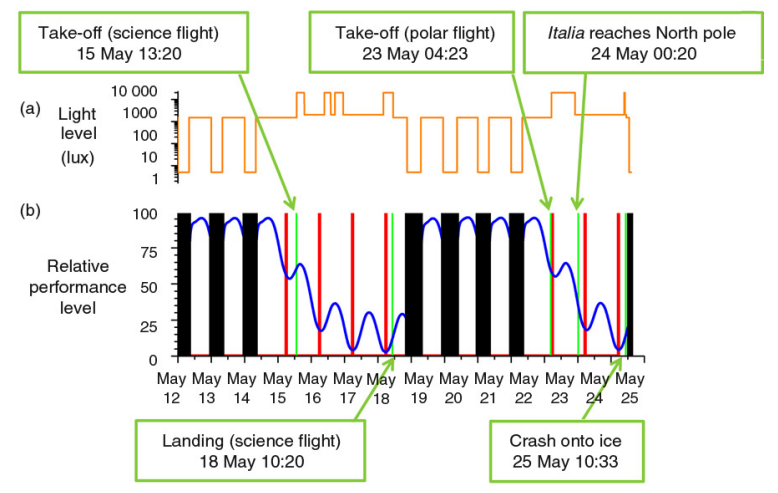

Fig. 2 CPSS plot of predicted performance relative to baseline for an individual with the sleep-wake cycles of General Umberto Nobile from 12 to 25 May. (a) Estimated light levels (lux). (b) Relative performance level, compared to a well-rested baseline. Sleep times are black boxes; times of core body temperature minimum, which reflect the expected times of worst performance, are red vertical lines; key events are green vertical lines; and the performance curve is blue.

and sleep episodes are needed for recovery, assuming one is able to sleep fully during each sleep episode, and assuming the sleep episode is of sufficient length (Bianchi 2014). Nobile does not directly address how much or how well he slept after the science mission, although he does note that after the flight he sent the crew to quarters to rest before embarking upon the polar flight. Therefore, the assumption is made that Nobile and his crew slept for as long as desired, without curtailment by any set wake-up times, until it was time to prepare for the polar flight. Given the multiple physiologic and other factors governing sleep duration, one would expect 2 days of extended sleep duration (i.e., $10 \mathrm{~h}$ ), before returning to normal sleep duration (i.e., $8 \mathrm{~h}$ ). However, to bolster the argument that Nobile was as well-rested as he could have been before embarking on the polar flight, we also simulated the unlikely scenario of 4 days with $10 \mathrm{~h}$ of sleep per night between the landing of the science/exploration flight (18 May) and the launch of the polar flight (23 May). The two simulations gave near-identical results at the time of the crash. Of note, the continuous light exposure during the 100-h sleep deprivation did not cause a circadian phase shift per the model, probably because the light exposure was long enough to include both times at which circadian phase advances and the phase delays in response to light would occur.

As alluded to earlier, it is not clear exactly when Nobile awoke prior to the polar flight, though some deductions can be made from modelling his sleep-wake patterns and from his own writings. Based on the amount of sleep he had likely obtained since the science/exploration flight, and based on the circadian rhythmicity demonstrated by the CPSS model, Nobile would not likely have been drowsy enough to fall asleep during the afternoon or evening of 22 May. And as already mentioned, Nobile received several telegraphs from the meteorological station in Tromsø throughout this time frame. Moreover, given the fact that Nobile and his crew were about to undertake something nobody had done before-land a scientific party at the North Pole-it is reasonable to conclude that he, as the commander, would have been personally attending to the various details inherent to preparation for such an endeavour, for example, ensuring the hydrogen bags were properly filled, ensuring the appropriate amount of petrol was loaded, ensuring the airship was in proper working order without mechanical problems and other such tasks. The weather reports would have been only one of many different details demanding Nobile's attention before launch. So while he may have sent the crew to quarters for rest, it is very likely that he himself did not go to sleep again after having awakened sometime on the morning of 22 May-most likely between 08:00 and 10:00. The crash of the Italia occurred at 10:33 on 25 May; at that time, Nobile would have experienced continued wakefulness in excess of $72 \mathrm{~h}$.

Estimates of the ambient light conditions experienced by Nobile can be made within an order of magnitude, based on his descriptions of whether the airship was in the direct sunlight or in the clouds throughout its journey. During the time of the year of those polar flights, the sun was above the horizon throughout the entire day, but at a low angle. Any such estimation of light intensity needs to take into account the effect of the albedo (i.e., the amount of sunlight reflecting off the ice, snow or water), which would be expected to increase the overall amount of light exposure experienced by the crew. On the other hand, this reflectance would have been tempered by the periods of fog that blocked the sunlight. Given these variances, it is difficult to accurately estimate the luminance at any given point in the journey of the Italia. However, an important point to remember is that the light exposure would have been constant, with no interruption by nighttime darkness at this time of the year. With these precautions in mind, we have estimated the environmental light exposure using data gathered from the Arctic and reported in the literature (Hisdal 1982).

Based on these observations and inferences, we constructed a raster plot describing the sleep-wake patterns of Nobile, along with the estimated light levels to which he was likely exposed (Fig. 1). In a raster plot, the days are shown vertically and the time of day is shown horizontally. The CPSS model was used to predict performance based on this sleep-wake and light schedule (Fig. 2). For a normal, rested individual on a regular schedule, the 
values of predicted performance (from CPSS) would be $81 \%$ of maximum after $16 \mathrm{~h}$ of wakefulness, and $50 \%$ of maximum after $24 \mathrm{~h}$ of wakefulness. The model predicts that an individual in Nobile's condition would have exhibited significantly impaired performance at the time of the crash of the Italia, with a predicted value of approximately $15 \%$ of maximum. Note that the predicted performance at the time of the accident was not the absolute minimum for the period surveyed, as a slight upward trend in performance due to circadian rhythmicity is noted just before the crash. However, critical decisions were made before the time of the crash, as detailed above.

\section{Evidence for fatigue-related errors}

There is a difference between noting that an operator was sleep-deprived at the time of a mishap, and claiming that the mishap was in fact fatigue-related. To make such a claim, one must show that the key operator(s) made errors attributable to sleep deprivation, and that these errors were integral to the sequence of events leading to the mishap. In the case of the Italia, this task is made more difficult for several reasons: (i) although an inquiry into the accident was performed by the Italian government, the convening authority was likely biased in their assessment of cause and their assignment of blame; (ii) there was no wreckage to analyse, and hence no physical evidence from which to derive clues regarding causation; and (iii) witness statements are limited by the remembrances of those who had survived the crash, and had then spent several weeks in an Arctic survival situation, so precise memory of important facts related to the crash may not be accurate. Nonetheless, some important observations and conclusions regarding the crash of the Italia can be made.

Based on his sleep-wake schedule, Nobile was significantly sleep-deprived at the time of the crash. It may be surmised that he was experiencing significant neurocognitive impairment as a result. We will now argue that Nobile made three sequential command decision errors that led directly to an overall loss of hydrogen lift gas, and therefore led directly to the mishap. Because these errors are the types of errors seen during sleep deprivation (Table 1), we conclude that the crash of the Italia was partially fatigue-related.

\section{Fatigue-related error \#1: incorrect assessment of dynamic versus static lift}

The first problem began at 09:25 on the morning of 25 May, when the ship's elevator control mechanism jammed in the "down" position; it is not known if the cause was mechanical or temperature-related. This forced the airship to descend rapidly, with the potential for impacting the ice. In response to this predicament, Nobile appropriately ordered the engines to be stopped. The result was a cessation of the downward aerodynamic pressure generated by the engines and air flow over the airship's hull that was forcing the airship progressively lower, towards the ice. (Of note, dynamic lift is that force generated by the flow of air over flight control surfaces, e.g., the elevator of the airship, due to the propulsion generated by the engines. By contrast, static lift is the principle of buoyancy due to a contained gas that is of lesser density than atmospheric air.) With the engines stopped, the Italia was now "light" because of hydrogen gas and the static lift it produced. It therefore started to rise like a hydrogen-filled balloon. Nobile states:

As I had foreseen, the moment the engines were stopped the descent slowed down abruptly, and about $250 \mathrm{ft}$. from the pack it ceased altogether. We began to rise gently. (1961: 152)

However, Nobile now did something of questionable value; in an attempt to decrease the rise of the airship due to the static lift, he ordered the gas valves to be opened to release some amount of hydrogen lift gas:

While we were slowly rising, Viglieri had released the elevator by a sharp blow. I ordered Cecioni to take it to pieces and examine the mechanisms. As he worked, the airship went on rising. Some time before I had opened all the air valves, so that the gas pressure had been reduced below zero. Now it showed signs of going up again. I kept an eye on the pressure-gauges ... During the ascent I saw the pressure-gauges register a slight rise. At a certain point I noticed that the pressure in the last compartment of the stern was much higher than in the others. I then let out a little gas, to equalize the pressure in this compartment with that of the others. We were still going up. (1961: 152-153)

Thus, Nobile gave two separate orders to release hydrogen lift gas - the first one in which he ordered all the valves opened, followed by a second order to equalize the pressures. This release of gas ordered by Nobile is also mentioned in the memoirs of crew member Trojani (1964).

The descent due to the jammed elevator control was a result of downward aerodynamic forces, and appropriately halted by a cessation of the motors. However, the consequent rise in altitude was a direct result of static lift, which Nobile counteracted by ordering the release of lift 
gas. Although this was sensible from the standpoint of correcting a problem of static lift, it was ultimately an incorrect choice because the ascent had resulted from a loss of dynamic (downward) lift - not an increase in static lift; it should have therefore been solved by re-engaging dynamic lift with a restart of the engines. This would have been the appropriate action once the elevator control problem had been corrected. The amount of hydrogen gas, that is, the static lift, had presented no problem thus far in the journey. The release of critical lift gas is a decision that is irreversible, and one which potentially compromises the operation of an air vehicle dependent in large part on the static lift generated by such gas. In this context, it is clear that Nobile's choice of action to counteract the airship's rise was incorrect.

Nobile had solved the problem of dynamic lift, followed by solving the problem of static lift, each in the manner appropriate to that problem. But he failed to synthesize the relationship of the static lift problem to the dynamic lift problem, and the more appropriate way of addressing the overall situation. In other words, he failed to synthesize available data so as to execute the appropriate response, and he demonstrated deterioration of performance requiring divergent thinking (i.e., the evaluation of multiple potential solutions to a given problem). These are types of error seen in sleep deprivation (Table 1).

\section{Fatigue-related error \#2: gas loss from increasing altitude}

As the airship continued to rise, Nobile ordered the ship above the fog on the suggestion of crew member Mariano, who wished to take a sextant reading on the sun. Such information would help them better identify their location and so determine how best to get back to base. To get above the clouds, they had to climb to an altitude of approximately 2700 feet, which would lead to an expansion of the hydrogen lift gas and a subsequent increase in the pressure inside the gas bags. Eckener has explained in greater detail the physics of gas behaviour for this specific case:

... the product of pressure multiplied by volume remains practically constant as long as the temperature of the gas is not changed. If a balloon is rising, the pressure of the surrounding atmosphere naturally decreases with increasing altitude, in fact diminishing by approximately 1 per cent for every 330 feet of increased altitude. According to Boyle's and Mariotte's Law the gas enclosed within the balloon's envelope must expand by a corresponding 1 per cent, in order for the original value of the pressure multiplied by the volume to remain constant. If the balloon were not 100 per cent full, or if it is made of an elastic material, then the gas would simply expand. But if it were previously completely filled, then, if it is not to burst, it must release gas through a safety-valve until the inner gas pressure again equals that of the outside atmosphere. A completely filled balloon will therefore pay for each 330 foot gain in altitude with the loss of 1 per cent of its buoyant gas content. (1958: 186-187)

Because of this potential for gas expansion, the airship's gas bags were equipped with automatic valves that opened when the internal pressure reached a specified level. Such a mechanism ensured the internal pressure never got so great so as to burst the gas bag, producing a catastrophic loss of lift gas.

After Nobile had ordered the release of some lift gas it is not known exactly at what level the ship's gas bags achieved the height of full expansion such that the automatic valves would begin to operate, but Nobile later noted that they eventually climbed to a height of 3300 feet. With the loss of $1 \%$ of lift gas for every 330 feet up to 3300 feet, this amounts to a potential loss of $9.24 \%$ of the total lift capacity for the Italia.

Whatever amount of gas lost on account of the altitude increase would be in addition to whatever was lost as a result of Nobile's earlier orders. While the request for a navigational reading was justified, and understandable given the fact that the ship was already rising in altitude, the granting of such a request needed to be weighed against the altitude ultimately required to get above the clouds. Specifically, if the required altitude was above the height of full expansion, getting such a reading would be ill-advised. While a solar navigational fix would be helpful, it was not absolutely critical to the immediate task of returning the ship and its crew back to base. Based on Eckener's analysis, it would appear that in this particular situation, the decision to get the sextant reading was in retrospect an incorrect one and an elementary error for somebody like Nobile, who had extensive knowledge of aeronautical engineering principles. This error in assessing relative risk of actions is another type of error seen during sleep deprivation (Table 1). Therefore, the decision to take the ship to a height above the clouds that likely led to automatic valving would be the second fatigue-related error in the mishap sequence.

\section{Fatigue-related error \#3: effects of direct sunlight exposure on gas and lift}

The airship climbed above the ice fog and cloud bank layer, emerging from the clouds at 2700 feet. 
This introduces another factor to be considered - that of temperature, and the heating of the hydrogen gas due to its exposure to direct sunlight. The increased heating will cause the gas to expand, and the pressure within the gas bags to increase. At some point, automatic valving will ensue, just as it does when pressure rises as a result of altitude. In his aforementioned analysis, Eckener describes the relationship between sunlight, temperature and volume of a gas as follows:

... when a quantity of gas is heated while the pressure remains constant the gas volume increases in direct proportion; while the gas pressure likewise increases if the gas is heated and the volume is held constant. This change in volume is always proportional to the absolute temperature. ... if the pressure is constant, a rise of 3 degrees Centigrade in the gas temperature, compared to that of the surrounding air, increases the gas volume and correspondingly the lift by 1 per cent. (1958:187)

Nobile notes that after they emerged above the cloud layer they remained there for several more minutes, actually climbing even higher-from 2700 to 3300 feetwhile the crew members made their observations. They eventually descended back into the fog and continued descent until they were flying along at altitudes between 600 and 900 feet. At this point, Nobile curiously notes: "The dirigible was still light, so to keep it at the proper height we had to hold the nose down" (Nobile 1961: 155). This would be consistent with expanded gas that had momentarily retained the heat supplied by the sun. But as that heat dissipated upon descent into the fog bank, and the gas contracted, decreasing its pressure and lift, a predictable effect followed. Just a few minutes after Nobile's observation that the ship was light, crew member Cecioni declared, "We are heavy!" (Nobile 1961: 155). At that point, they were pointed nose-up at 8 degrees, yet the airship continued an uncommanded descent. In order to generate more dynamic lift, Nobile ordered the third engine to be restarted and the two running engines to be accelerated. He likewise ordered the nose to be tilted higher, up to 20 degrees. As he states, "The dynamic lift obtained in this way must certainly have represented several hundredweight" (1961: 155). Despite these efforts, the airship's descent did not decrease; in fact, it actually seemed to increase, which would be consistent with a continued cooling and contraction of lift gas. A few moments later, the airship crashed onto the ice.

While it is difficult to say precisely by just how much the hydrogen gas was heated, and therefore by just how much it expanded and/or increased in pressure, this effect of solar heating on an airship was not insignificant. The phenomenon was known to Nobile; he writes about it regarding an earlier instance with his previous airship, the Norge, when, interestingly enough, he was also requested to climb above the Arctic fog to get a navigational fix on the sun:

It was at this point that Riser-Larsen proposed that we should ascertain our position by taking the height of the sun. For that we need to climb above the fog...By this time the ship was light, and it climbed rapidly through the fog ... until we at last saw the sun. Riiser-Larsen took an altitude with his sextant. Meanwhile, we had reached the height of full expansion, and the sun had warmed the gas which quickly expanded: I saw the pressure in the manometers rapidly rising. I opened all the valves, but this did not check our ascent ... while the pressure in the gauges went on rising: 60, 70, $80 \mathrm{~mm}$. A really critical situation ... If this went on, in a few moments the valves would open automatically, causing a disastrous loss of hydrogen ... The nose came down and we began to descend: the pressure dropped. I drew a long breath of relief. (1961: 75)

Therefore, exposure to direct sunlight and its effect on heating the lift gas was a significant matter, and the longer one remained in the sunlight, the more serious this matter would become.

It is known that the initial mishap sequence began at 09:25, when the elevator control became jammed. This situation was corrected and the ship started to rise, all presumably within the period of a few minutes. Over the next several minutes, the ship climbed to a height above the cloud layer at 2700 feet. As mentioned earlier, Nobile stated they eventually achieved a height of 3300 feet and had apparently been at that level for some period of time by 09:55, at which point Nobile states they "flew for a few minutes longer above the fog" (1961: 153). At some point afterwards, they began their descent back into the clouds, and ultimately crashed at 10:33. It is therefore reasonable to conclude that the ship was in direct sunlight for at least $30 \mathrm{~min}$.

Despite Nobile understanding the ramifications of staying in direct sunlight for a prolonged period of time, and demonstrating such knowledge in his handling of the Norge, he does not act appropriately with the Italia. He did not apply the basic gas laws governing pressure, volume and temperature. These types of errors (i.e., attention to what is considered a secondary problem and calculation problems) are also seen with sleep deprivation (Table 1) and contributed to what is here described as his third fatigue-related error in the mishap sequence. 


\section{Argument against automatic valving, with rebuttal}

There is evidence contradicting the theory that a loss of lift gas was the proximate cause of the mishap. Crew member Trojani, who as mentioned earlier was in the gondola of the ship visually monitoring the gauges that displayed the gas pressures during their ascent after the near-impact with the ice has also noted in his memoirs that even though the engines were shut down, the crew did not hear the characteristic hissing sounds made by the automatic valves when opening (Trojani 1964). However, the assertion that there was no automatic valving because the crew did not hear it is valid only if one assumes that the crew's hearing was normal at the time. In reality, their hearing almost certainly was not normal because of a phenomenon known as the "temporary threshold shift". The concept of the temporary threshold shift, sometimes referred to as "auditory fatigue", is the downward shift in hearing acuity experienced by people who have been exposed to loud noise (i.e., over $90 \mathrm{~dB}$ ) for a continuous period of time (i.e., several hours) (Wu et al. 1989; Quaranta et al. 1998). The temporary threshold shift results mostly from the autonomic contraction of a muscle that dampens the motion of the bones of the middle ear in response to the incoming vibrational sound energy. The phenomenon is well described in safety and health circles, and can be reliably induced, for example, upon prolonged exposure to loud music (Le Prell et al. 2012).

In the case at hand, the Italia's the engines had been running constantly, pushing the ship relentlessly against head winds, for hours - even days - until the discovery of the jammed elevator control, at which point the engines were ordered stopped. These engines were very noisy, as attested by Trojani himself (Trojani 1964). Prolonged noise itself is fatiguing (Landstrom 1990; Kjellberg et al. 1996). Noise also has detrimental effects upon performance (Suter 1989; Nassiri et al. 2013) and has been associated with an increase in workplace accidents and occupational injuries (Toppila et al. 2009; Cantley et al. 2015). These direct effects of noise would have been in addition to the effects of fatigue on crew performance. Upon the sudden cessation of the loud noise of the engines, the crew members would be expected to experience a temporary threshold shift and would therefore be literally unable to hear the characteristic hissing sound of the automatic valving. Therefore, failure to hear evidence of automatic valving is not evidence that it did not occur, and the hypothesis that a loss of lift gas was a critical factor in the crash of the Italia remains valid.

\section{Conclusion}

A review of the historical record strongly suggests that the commander of the airship Italia was significantly sleep-deprived at the time of the accident. The CPSS model predicts extremely poor performance at the time of the accident because of sleep deprivation and lighting conditions. Such sleep deprivation is now well known to be associated with significant deterioration in cognition, decision-making and performance. The historical evidence furthermore reveals three decisions made by Nobile that appear to be integral to a mishap sequence and which are here postulated to be fatigue-related. First, there was the inappropriate release of gas to halt a static lift ascent that was actually a result of loss of the downward dynamic force produced by the engines, which had just been shut down. Secondly, Nobile uncharacteristically ordered the airship above the fog bank, resulting in lift-gas expansion and a likely loss of such gas due to automatic valving. Thirdly, Nobile ill-advisedly allowed the ship to remain in direct sunlight for several minutes, resulting in heating, further expansion, and further loss of lift gas due to automatic valving. These errors are of the kinds seen in sleep-deprived individuals. The net result of these errors was an overall loss of a critical volume of lift gas. Once the ship descended and flew back into the fog bank, the heated gas cooled and contracted, resulting in a significant loss of lift; sustained flight at this point could no longer be maintained. Therefore, the crash of the airship Italia is here considered partially a fatigue-related mishap.

This paper is not an indictment of General Nobile or his ability to command, nor is it meant to malign his achievements as an Arctic explorer and airship designer. Quite the contrary - it was Nobile's intellect and stamina that enabled the expeditions to achieve what they had up until this point. Nobile cannot be faulted for not appreciating the cognitive effects of sleep loss at a time when such effects were neither well known nor appreciated. The science of sleep deprivation and circadian rhythmicity, however, is now well established and can be applied to this accident so that lessons can be learned for future missions.

The lessons to be learned from this analysis are: (i) fatigue due to sleep loss and circadian rhythm disruption has significant performance implications and significantly increases the risk of an accident; (ii) appropriate fatigue risk management can be integral to the safe accomplishment of polar exploration missions; and (iii) fatigue modelling can play an important role in an overall fatigue risk management effort when used to evaluate different potential schedules, and to suggest times of predicted poor performance so that countermeasures (e.g., naps, 
caffeine) can be planned appropriately (Rosekind et al. 1994; Dawson \& McCullough 2005). We welcome continued discussion on this topic.

\section{Acknowledgements}

The authors thank Vanessa A. Folkerts, who at the time was a participant in the Scripps College Post-Baccalaureate Premedical Program, Department of Neurosurgery, Cedars-Sinai Medical Center, Los Angeles; she provided useful research for the narratives of this paper, as well as text translation from the Italian. The authors also thank Christian Gelzer, Historian at the National Aeronautics and Space Administration Neil A. Armstrong Flight Research Center in California, as well as Michael Gorn, Research Associate, Smithsonian Institution, National Air and Space Museum, for their insightful comments in the review of this paper. Additionally, the authors thank Dan L. Chiappe, Professor in Psychology (Human Factors) at California State University-Long Beach, for his thoughtful insights in the review of this paper. Finally, the authors thank Richard S. Williams, Chief Health and Medical Officer, National Aeronautics and Space Agency and two anonymous reviewers for their thoughtful reviews of this paper. EBK is supported by grants from the National Institutes of Health and the National Space Biomedical Research Institute through NASA NCC 9-58.

\section{Disclaimer}

The opinions expressed in this paper are solely those of the authors and do not represent the opinions or viewpoints of the National Aeronautics and Space Agency, the Brigham and Women's Hospital, Harvard Medical School or any funding agency.

\section{References}

Aas S. 2005. New perspectives on the Italia tragedy and Umberto Nobile. Polar Research 24, 5-15.

Alhola P. \& Paivi P.-K. 2007. Sleep deprivation: impact on cognitive performance. Neuropsychiatric Disease and Treatment 3, 553-567.

Anonymous 1930. Official report blames Nobile for Italia disaster. Free Lance-Star, Fredericksburg, VA, Tuesday, 18 Feb., p. 3. Accessed on the internet at http://news.google.com/newspapers? $\mathrm{nid}=12988 \mathrm{dat}=193002188 \mathrm{id}=$ pOVNAAAAIBAJ\&sjid $=\mathrm{gYo}$ DAAAAIBAJ\&pg=7386,1296809 on 11 June 2014 .

Arendt J. 2012. Biological rhythms during residence in polar regions. Chronobiology International 29, 379-394.

Banks S. \& Dinges D.F. 2007. Behavioral and physiological consequences of sleep restriction. Journal of Clinical Sleep Medicine 3, 519-528.
Belenky G., Wesensten N.J., Thorne D.R., Thomas M.L., Sing H.C., Redmond D.P., Russo M.B. \& Balkin T.J. 2003. Patterns of performance degradation and restoration during sleep restriction and subsequent recovery: a sleep doseresponse study. Journal of Sleep Research 12, 1-12.

Bermudez E.B., Klerman E.B., Czeisler C.A., Cohen D.A., Wyatt J.K. \& Phillips A.J. 2016. Prediction of vigilant attention and cognitive performance using self-reported alertness, circadian phase, hours since awakening, and accumulated sleep loss. PLoS One 11, e0151770, doi: http://dx.doi.org/10 1371/journal.pone.0151770

Bianchi M.T. 2014. Sleep deprivation and disease. New York: Springer Science.

Borbély A.A. 1982. A two process model of sleep regulation. Human Neurobiology 1, 195-204.

Cagni U. 1930. Commissione d'indagini per la spedizione polare de Ministero della marina. (Commission of investigation for the polar expedition of the Admiralty.) Rome: Ministero della Marina.

Caldwell J.A., Caldwell J.L., Brown D.L. \& Smith J.K. 2004. The effects of 37 hours of continuous wakefulness on the physiological arousal, cognitive performance, self-reported mood, and simulator flight performance of F-117A pilots. Military Psychology 16, 163-181.

Cantley L.F., Galusha D., Cullen M.R., Dixon-Ernst C., Rabinowitz P.M. \& Neitzel R.L. 2015. Association between ambient noise exposure, hearing acuity, and risk of acute occupational injury. Scandinavian Journal of Work and Environmental Health 41, 75-83.

Carskadon M.A. 1993. Micro sleep. In M.A. Carskadon (ed.): Encyclopedia of sleep and dreaming. Pp. 373-374. New York: Macmillan.

CASA (Civil Aviation Safety Authority) 2014. Biomathematical fatigue models guidance document. Canberra: Australian Government.

Cohen D.A., Wang W., Wyatt J.K., Kronauer R.E., Dijk D.-J., Czeisler C.A. \& Klerman E.B. 2010. Uncovering residual effects of chronic sleep loss on human performance. Science Translational Medicine 2, 1-8.

Cross W. 2002. Disaster at the Pole: the crash of the airship Italia and the 1928 Nobile expedition to the North Pole. Guilford, CT: Lyons Press.

CSMR (Committee on Sleep Medicine and Research) 2006. Sleep physiology. In H.R. Colten \& B.M. Altevogt (eds.): Sleep disorders and sleep deprivation: an unmet public health problem. Pp. 33-53. Washington, DC: National Academies Press.

Dawson D. \& McCulloch K. 2005. Managing fatigue: it's about sleep. Sleep Medicine Reviews 9, 365-380.

Dawson D. \& Reid K. 1997. Fatigue, alcohol and performance impairment. Nature 388, 235.

Dean D.A. II., Forger D.B. \& Klerman E.B. 2009. Taking the lag out of jet lag though model based schedule design. PLoS Computational Biology 5, e1000418, doi: http://dx.doi.org/10. 1371/journal.pcbi.1000418

Dijk D.J. \& Czeisler C.A. 1994. Paradoxical timing of the circadian rhythm of sleep propensity serves to consolidate sleep and wakefulness in humans. Neuroscience Letters 166 , 63-68. 
Dinges D.F. \& Kribbs N.B. 1991. Performing while sleepy: effects of experimentally-induced sleepiness. In T.H. Monk (ed.): Sleep, sleepiness and performance. Pp. 97-128. Chichester: Wiley.

Dinges D.F. \& Powell J.W. 1985. Microcomputer analysis of performance on a portable, simple visual RT task sustained operations. Behavioral Research Methods, Instrumentation and Computers 17, 652-655.

Doran S.M., Van Dongen H.P. \& Dinges D.F. 2001. Sustained attention performance during sleep deprivation: evidence of state instability. Archives of Italian Biology: Neuroscience 139, 253-267.

Duffy J.F. \& Czeisler C.A. 2009. Effect of light on human circadian physiology. Sleep Medicine Clinics 4, 165-177.

Durmer J.S. \& Dinges D.F. 2005. Neurocognitive consequences of sleep deprivation. Seminars in Neurology 25, 117-129.

Eckener K. 1958. A note on the technology and development of the zeppelin airship. In H. Eckener (ed.): My zeppelins. Pp. 185-216. London: Putnam \& Co.

Gander P.H., MacDonald J.A., Montgomery J.C. \& Paulin M.G. 1991. Adaptation of sleep and circadian rhythms to the Antarctic summer: a question of Zeitgeber strength. Aviation, Space and Environmental Medicine 62, 1019-1025.

Gokhale B.N. 2010. Report on accident to Air India Express Boeing 737-800 Aircraft VT-AXV on 22nd May 2010 at Mangalore, New Delhi. New Delhi: Ministry of Aviation.

Goode J.H. 2003. Are pilots at risk of accidents due to fatigue? Journal of Safety Research 34, 309-313.

Harrison Y. \& Horne J.A. 1999. One night of sleep loss impairs innovative thinking and flexible decision making. Organizational Behavior and Human Decision Processes 78, 128-145.

Harrison Y. \& Horne J.A. 2000. The impact of sleep deprivation on decision making: a review. Journal of Experimental Psychology: Applied 6, 236-249.

Hisdal V. 1982. Snow-sky and water-sky luminance at an Arctic Station. Polar Research 2, 3-15.

Horne J. \& Moseley R. 2011. Sudden early-morning awakening impairs immediate tactical planning in a changing "emergency" scenario. Journal of Sleep Research 20, 275-278.

Jewett M.E., Dijk D-J., Kronauer R.E. \& Dinges D.F. 1999. Dose-response relationship between sleep duration and human psychomotor vigilance and subjective alertness. Sleep 22, 171-179.

Jewett M.E. \& Kronauer R.E. 1998. Refinement of a limit cycle oscillator model of the effects of light on the human circadian pacemaker. Journal of Theoretical Biology 192, 455-465.

Jewett M.E. \& Kronauer R.E. 1999. Interactive mathematical models of subjective alertness and cognitive throughput in humans. Journal of Biological Rhythms 14, 588-597.

Joern A.T., Shurley J.T., Brooks R.E., Guenter C.A. \& Pierce C.M. 1970. Short term changes in sleep patterns on arrival at the South Polar plateau. Archives of Internal Medicine 125, 649-654.

Killgore W.D.S., Balkin T.J. \& Wesensten N.J. 2006. Impaired decision making following $49 \mathrm{~h}$ of sleep deprivation. Journal of Sleep Research 15, 7-13.
Kjellberg A., Sköldström B., Andersson P. \& Lindberg L. 1996. Fatigue effects of noise on aeroplane mechanics. Work $\theta$ Stress $10,62-71$.

Lamond N., Jay S.M., Dorrian J., Ferguson S.A., Jones C. \& Dawson D. 2007. The dynamics of neurobehavioural recovery following sleep loss. Journal of Sleep Research 16, 33-41.

Landstrom U. 1990. Noise and fatigue in working environments. Environment International 16, 471-476.

Le Prell C.G., Dell S., Hensley B., Hall J.W. III., Campbell K.C.M., Antonelli P.J., Green G.E., Miller J.M. \& Guire K. 2012. Digital music exposure reliably induces temporary threshold shift (TTS) in normal hearing human subjects. Ear Hear 33, e44-e58.

Libedinsky C., Massar S.A.A., Ling A., Chee W., Huettel S.A. \& Chee M.W.L. 2013. Sleep deprivation alters effort discounting but not delay discounting of monetary rewards. Sleep 36, 899-904.

Lo J.C., Groeger J.A., Santhi N., Arbon E.L., Lazar A.S., Hasan H., von Schantz M., Archer S.N. \& Dijk D.J. 2012. Effects of partial and acute total sleep deprivation on performance across cognitive domains, individuals and circadian phase. PLoS One 7(9), e45987, doi: http://dx.doi.org/10.1371/journal. pone.0045987

Maddox W.T., Glass B., Wolosin S.M., Savarie Z., Bowen C., Matthews M.D. \& Schnyer D. 2009. The effects of sleep deprivation on information-integration categorization performance. Sleep 3, 1439-1448.

Mitler M.M., Carskadon M.A. \& Czeisler C.A. 1988. Catastrophes, sleep, and public policy: consensus report. Sleep 11, 100-109.

Moller H.J., Kayumov L., Bulmash E.L., Nhan J. \& Shapiro C.M. 2006. Simulator performance, microsleep episodes, and subjective sleepiness: normative data using convergent methodologies to assess driver drowsiness. Journal of Psychosomatic Research 61, 335-342.

Monk T.H. 2007. Practical consequences of fatigue-related performance failures. Sleep 30, 1402-1403.

Monk T.H. \& Carrier J. 1997. Speed of mental processing in the middle of the night. Sleep 20, 399-401.

Moss T.H. \& Sills D.L. 1981. The Three Mile Island nuclear accident: lessons and implications. New York: New York Academy of Science.

Nassiri P., Monazam M., Fouladi Dehaghi B., Ibrahimi Ghavam Abadi L., Zakerianl S.A. \& Azam K. 2013. The effect of noise on human performance: a clinical trial. International Journal of Occupational and Environmental Medicine 4, 87-95.

Neri D.F. 2004. Preface: fatigue and performance modeling workshop, June 13-14, 2002. Aviation, Space and Environmental Medicine 75, A1-A3.

Nilsson J.P., Söderstrom M., Karlsson A.U., Lekander M., Akerstedt T., Lindroth N.E. \& Axelsson J. 2005. Less effective executive functioning after one night's sleep deprivation. Journal of Sleep Research 14, 1-6.

Nobile U. 1961. My polar flights: an account of the voyages of the airships Italia and Norge. F. Fleetwood (trans.) London: Frederick Muller. 
NRC (US Nuclear Regulatory Commission) 1987. Report on the accident at Chernobyl nuclear power station. Washington, DC: US Government Printing Office.

NTSB (National Transportation Safety Board) 1990. Marine accident report: grounding of the U.S. tankship Exxon Valdez on Bligh Reef, Prince William Sound near Valdez, Alaska, March 24, 1989. NTSB/MAR-90/04. Washington, DC: National Transportation Safety Board.

NTSB (National Transportation Safety Board) 1994. Aircraft accident report: uncontrolled collision with terrain, American International Airways flight 808, Douglas DC-8-61, N814CK, U.S. Naval Air Station, Guantanamo Bay, Cuba, August 18, 1993. NTSB/AAR-94/04. Washington, DC: National Transportation Safety Board.

Pack A.I., Pack A.M., Rodgman E., Cucchiara A., Dinges D.F. $\delta$ Schwab C.W. 1995. Characteristics of crashes attributed to the driver having fallen asleep. Accident Analysis and Prevention 27, 769-775.

Peroni I. 2009. Into thin air: Umberto Nobile, Fascist explorer. History Today 59, 6.

Porkka-Heiskanen T., Alanko L., Kalinchuk A. \& Stenberg D. 2002. Adenosine and sleep. Sleep Medicine Reviews 6, 321-332.

Quaranta A., Portalatini P. \& Henderson D. 1998. Temporary and permanent threshold shift: an overview. Scandinavian Audiology Supplement 48, 75-86.

Rahman S.A., Flynn-Evans E.E., Aeschbach D., Brainard G.C., Czeisler C.A. \& Lockley S.W. 2014. Diurnal spectral sensitivity of the acute alerting effects of light. Sleep 37, 271-281.

Roach G.D., Petrilli R.M., Dawson D. \& Thomas M.J.W. 2006. The effects of fatigue on the operational performance of flight crews in a B747-400 simulator. In: Proceedings of Seventh International AAvPA Symposium: Evolving System Safety. Sydney: Australian Aviation Psychology Association.

Roehrs T., Burduvali E., Bonahoom A., Drake C. \& Roth T. 2003. Ethanol and sleep loss: a "dose" comparison of impairing effects. Sleep 26, 981-985.

Rosekind M.R., Graeber R.C., Dinges D.F., Connell L.J., Rountree M.S., Spinweber C.L. \& Gillen K.A. 1994. Crew factors in flight operations IX: effects of planned cockpit rest on crew performance and alertness in long-haul operations. NASA Technical Memorandum 108839. Washington, DC: National Aeronautics and Space Administration.

Ross J.K., Arendt J., Horne J. \& Haston W. 1995. Night-shift work in Antarctica: sleep characteristics and bright light treatment. Physiology and Behavior 57, 1169-1174.
Simmons G. 1965. Target: Arctic-men in the skies at the top of the world. New York: Chilton Books.

Spencer M.B., Stone B.M., Rogers A.S. \& Nicholson A.N. 1991. Circadian rhythmicity and sleep of aircrew during polar schedules. Aviation, Space and Environmental Medicine 62, 3-13.

Suter A.H. 1989. The effects of noise on performance. Technical Memorandum 3-89. AMCMS Code 611102.74A0011. Aberdeen, MD: US Army Human Engineering Laboratory.

Toppila E., Pyykkö I. \& Pääkkönen R. 2009. Evaluation of the increased accident risk from workplace noise. International Journal of Occupational Safety and Ergonomics 15, 155-162.

Trojani F. 1964. La coda di minosse: vita di un uomo, storia di un'impresa. (The code of Minos the life of a man, the history of a company.) Milan: U. Mursia \& Co.

Van Dongen H.P.A., Baynard M.D., Maislin G. \& Ginges D.F. 2004. Systematic interindividual differences in neurobehavioral impairment from sleep loss: evidence of trait-like differential vulnerability. Sleep 27, 423-433.

Van Dongen H.P.A., Maislin G., Mullington J.M. \& Dinges D.F. 2003. The cumulative cost of additional wakefulness: doseresponse effects on neurobehavioral functions and sleep physiology from chronic sleep restriction and total sleep deprivation. Sleep 26, 117-126.

Venkatraman V., Chuah Y., Huettel S.A. \& Chee M.W.L. 2007. Sleep deprivation elevates expectation of gains and attenuates response to losses following risky decisions. Sleep 30, 603-609.

Whitmire A.M., Leveton L.B., Barger L., Brainard G., Dinges D.F., Klerman E.B. \& Shea C. 2009. Risk of performance errors due to sleep loss, circadian desynchronization, fatigue, and work overload. In J.C. McPhee \& J.B. Charles (eds.): Human health and performance risks of space exploration missions: evidence reviewed by the NASA Human Research Program. NASA SP-2009-3405. Washington, DC: National Aeronautics and Space Administration.

Wu Y.X., Liu X.L., Wang B.G. \& Wang X.Y. 1989. Aircraft noise-induced temporary threshold shift. Aviation, Space and Environmental Medicine 60, 268-270.

Wyatt J.K., Cajochen C., Ritz-De Cecco A., Czeisler C.A. \& Dijk D.J. 2004. Low-dose repeated caffeine administration for circadian-phase-dependent performance degradation during extended wakefulness. Sleep 27, 374-381. 